\title{
The development of nursing professional identity in morocco: state of the art and avenues for research and education
}

\author{
Nada Ammari ${ }^{1 *}$, and Abdellah Gantare ${ }^{2}$ \\ 1,2, Hassan first University of Settat; Higher institute of health sciences; Laboratory of Health Sciences \\ and Technologies; Route de Casablanca BP 539 Settat, Morocco.
}

\begin{abstract}
Nursing is a major pillar for the achievement of national and global health goals, with a plethora of research documenting the effect of the state of nursing professional identity on different outcomes such as the quality of care, worker retention, and work satisfaction. This present paper examines the current state of professional nursing identity in the Moroccan context and introduces critical priorities for its progress. Using a logical inductive analysis, this article concludes that significant developments have occurred in Moroccan nursing in recent years, mainly the shift to universitybased education and initial formal recognition of nursing as a profession. Nonetheless, Professional identity remains mostly unexplored in Morocco, and research is increasingly required to evaluate its various attributes and inform decision-making in nursing education and practice. Recommendations related to the findings include prioritization of research on the knowledge base of nursing and its application in the Moroccan healthcare context, the establishment of innovative measures in education conducive to positive socialization into the profession, amendment of nursing social image, and the establishment of professional nursing ethics within the Moroccan healthcare system.
\end{abstract}

\section{Introduction:}

Nursing professional identity has been long associated with outcomes like worker retention[1], job satisfaction[2], good quality care[1] [3], and the overall tendency to create a more collaborative working atmosphere and achieving nursing goals[4]. The complexity of the concept and its context-dependent nature makes research highly needed in diverse social and cultural contexts, albeit very scarce in developing countries like Morocco.

The description of the professional role and its ethical standards and framework has to consider cultural influences as they are significantly impactful and shape nursing practice [5]. The additional element of nursing historically being in deep need of professional congruency and efficiency[6], accentuates the complexity of the discussions surrounding the nursing professional identity. This is observed through the recurrent call for alignment between theory and practice [1].

\footnotetext{
${ }^{*}$ Corresponding author: $\underline{\text { n.ammari@uhp.ac.ma }}$
} 
This paper provides a comprehensive response to the question of how Moroccan nursing is moving towards professionalism through the lens of nursing professional identity and its formation. Drawing from the theoretical exploration of the concept within the literature that analyses the concept, the paper takes a critical look at nursing in Morocco, its developments in education and legislation, and how the national health system policies and global changes have influenced its development. By aligning the current state of Moroccan nursing development with recent and substantial literature, we emphasize high-priority areas of significance in research and education, conducive to rapid growth in establishing nursing as a profession and eventual achievement of national and global health goals.

\section{Method:}

This discussion paper utilizes a logical inductive analysis method to arrive at generalizations effective for future empirical verifications. This involved, first, a reading and synthesis of literature reviews and book sections that analyze the concept of nursing professional identity, with a focus on the recent and significant scientific literature around the subject. Followed by the use of the available empirical evidence from official documents, rapports, and publications on Moroccan nursing, allowing for comparative analysis. This specific methodology was considered the most adequate to gain insight into the numerous components of nursing professional identity within the Moroccan sociohistorical context and respond to the research question.

\section{Results:}

\subsection{Professionalism and professional identity:}

Professionalism and being a professional have their roots in Aristotelian philosophy, where we find phronesis as a signifier for practiced wisdom. Phronesis is considered among intellectual virtues or excellences of the mind[7]. A profession is also identifiable through a professional group that possesses a specialized set of skills, based to some extent on esoteric knowledge[8]. This asset gives professionalism an aspect of high regard linked with the expectation of high-quality services Gardner and Shulman [3]defined as an exchange of prestige and social recognition for good quality services. Earning the title of a profession is thus conditioned by several criteria that are debated within the nursing literature[3,9]. There is a general understanding that the shift from being an occupation to a profession includes the presence of a defined and specialized knowledge base, control and authority over training and education in higher education institutions, the guarantee of competence through accreditation or registration systems, offering altruistic service to society, having a code of ethics, with the addition of a long period of socialization in the profession, and the control of one's professional activities [9, 10]. Styles [11]adds the element of autonomy and accountability. Gardner and Shulman mention other factors such as congruency between theory and practice, critical reflection on one's practice and experiential learning, adaptability to uncertainty, and contribution to the profession and other professionals [3, 12].

Nursing professional identity can be considered a subjective concept as well, the personal feeling of being a nurse [4] [1]. Or the degree of identification and internalization of a set of professional attributes and values[13]. It is the capacity for negotiation and balance between these two aspects, the established professional values and the subjective meaning of being a nurse, that leads to the maintenance and maturation of one's professional identity [1].

Professional identity is a multifaceted concept, as Fitzgerald [3] explains through her review of 60 articles published between the years 2000 and 2019. Her paper concludes that 
professional nursing identity encompasses five attributes: 1- actions and behaviors, 2knowledge and skills,3- values, beliefs, ethics, 4-context, and socialization 5- group and personal identity. The interplay between these elements influences the construction of an individual's professional identity and how they interpret it [3].

McCall and Simmons, through their concept of the interactive role [14], offer an understanding of this situational nature of identity. They assert that it involves what is conventional just like what is distinctive and the cultural expectations as well as individual personal identity. Their role identity theory postulates that the individual includes several role identities that are hierarchically classified. And so, the more favorable a role identity is for the overall self-conception, the more the individual seeks to use mechanisms to legitimize this identity [14]. Similarly, and in Tafjel and turner's social identity theory, we find the concept of group identity salience, the multiplicity of social identities, and their situational relevance and subjectivity [15].

The maturation of professional identity can be regarded as a continuum from weak to strong [4], indicating the degree of identification with the professional group[16]. This represents another aspect of Tajfel and turners social identity theory where social relationships and transactions that occur outside of conflicts of interest can be considered on a continuum, from interactions wholly determined by interpersonal relationships and individual characteristics to the other extreme of interactions between two or more individuals or groups of individuals entirely determined by their group membership[16]. And so, the more the individual identifies with their professional role, the more they will act out and behave by the attributes and characteristics linked to the professional group. This dynamic is crucial to understanding the degree of the sense of belonging and strength of the group identity.

The individual perception of role identity can become nuanced further through McCall and Simmons's theory. Their theory posits that individuals tend to develop exaggerated and idealistic perceptions and role identities of themselves. And so, they are in constant tension with the real world. This tends to form a motivation to reduce this tension and legitimize the role identity. This legitimization is first internal where the individual seeks consistency between the conduct carried out and the imagined vision of oneself in the social position and then the external audience, which is the society where individuals seek support and recognition for actions associated with the role occupied [14]. This gives professional identity an aspect of growth and change, motivated by the need for legitimization and cohesion with the environment and social context.

\subsection{Nursing within the Moroccan national healthcare system:}

The Moroccan healthcare system has gone through many changes in the last ten years because of significant political and socio-demographic shifts.

The demographic change, namely the increasing numbers of the elderly population, and globalization have put considerable pressure and strain on the healthcare sector. These observed transitions have led the world health organization (WHO) to call for many needed reforms and regulations in the healthcare sector in many of its reports[17].

The Moroccan government deployed Considerable efforts to reform its healthcare system, beginning with the explicit recognition of the right to healthcare access, social protection with medical coverage, and mutual aid or solidarity organized by the State that comes under the Moroccan Constitution of 2011. The conception of the 2025 health plan was a natural development that came in alignment with the socio-political reforms and presents an ambitious vision of a health care system oriented towards citizen-centered care[18].

Morocco Has also been committed to several international agreements[18], mainly with the World Health Organization and the united nations. The WHO has specified its priorities 
in several areas of action, including universal health coverage. However, the international subscription to the achievement of the Sustainable Development Goals (SDGs) by 2030 has primarily influenced the orientation of Moroccan health policies, particularly SDG 3 that aims to "ensure healthy lives and promote well-being for all at all ages."[18]

These envisioned goals, give rise to needed changes in the skills targeted within the different disciplines of health professions including nursing and lead to an emergent need for a unifying perspective, a clear and shared identity, and a nursing formation process that takes into account the different components of professional identity[17]. The national outlook on health care has inevitably led to an increasing focus on nursing professions and their development as an academic and scientific avenue.

The emergence of nursing began relatively late in Morocco compared to western societies through hospital-based training in the $60 \mathrm{~s}$ in state schools of nurses. Although the training has gone through some changes throughout the years, it remained fundamentally technical and hospital-based until very recently. The implementation of a university-based nursing educational system, as of 2013 that was generalized in 2017 in all nursing forming institutions, aimed towards more academic-oriented education of nurses, midwives, and other health-technical specializations. This new system aims to offer the opportunity for higher education through masters and Ph.D. Nonetheless, many Moroccan nurses have been earning $\mathrm{PhDs}$ and masters even before these changes, albeit being the result of engaging with other fields such as law, economics, and different areas of social sciences and other disciplines.

With these achievements realized, there remain many acknowledged challenges in the development of nursing in Morocco. Beginning with the deficit, quantitative and qualitative in the nursing workforce [18]. This poses a source of disparities that hinders the achievement of universal health coverage and threatens the resilience of the national health system[19]. This shortage grows more taxing as it is followed by a slow rhythm of recruitment, lack of sufficient public health funding, private-sector competition, brain drain globalization[20], and retirement rates that make compensation difficult for the public sector. [18]

As for nursing regulation, the formal publication of the Moroccan nursing legal frame was established in 2016 [21]. It defines a nurse as any person who provides, depending on the title or diploma that entitles them to it, nursing care. That includes what is preventive, curative, or palliative. Nurses also provide care to ensure the hygiene and comfort of the patient and participate in planning actions, supervision of management, training, and research in nursing. This definition also includes how nurses practice their profession under medical prescription, the supervision and responsibility of a doctor, or independently regarding their unique acts. Although these acts are defined as acts specific to nurses, they are established by healthcare facilities administrations, after consulting with the national council of the national order of nurses and the national council of the national order of physicians. And, with the national order of nurses yet not present in Morocco as of the making of this article, authorized nurses constitute themselves in a national professional association, governed by the law regulating the right of association. [21].

\section{Discussion:}

The achievement of national and global health objectives is dependent on the realization of nursing goals. the Moroccan 2025 health plan reflects this statement [18], where it explicitly mentions the requirement for clarifying descriptions of role profiles for healthcare professionals, development of professionalism, ethical standards, formulation of integrated and continued care, and humanization of healthcare structures with competence and empathy. This discussion, consequently, interprets the findings on the status of Moroccan nursing by considering those distinct goals along with the constituents of nursing professional identity. It accomplishes this through four main themes: the nursing knowledge base, development of 
autonomy and self-regulation, social recognition, sense of belonging, and finally, the ethical foundations of nursing.

\subsection{Knowledge base:}

The nursing knowledge base is the unique body of knowledge, expertise, and theoretical background for nursing [3]. Yet, some authors suggest that it is less common to discuss what nurses know [22]. The knowledge base of nurses lies at the root of competent and effective care and provides an incentive to involve nurses as contributors to broader decision-making and planning. It is the knowledge of nurses that makes their involvement in advanced roles meaningful[22]. Formal education and certification are strongly associated with the nursing knowledge base as they ensure nurses can maintain a level of professionalism in a constantly changing healthcare environment[3]. Historically, The move of nursing towards professionalization began with the transfer to university-based education[15] [9]. This development in nursing education goes far back into the 1950s and arguably even the 1920s in the united states, with the first nursing-related doctorate originating in 1924 at Teacher's College, Columbia University, designed to prepare nurses to teach at the university level [23]. This shift in focus led to breakthroughs in the knowledge base of nursing beginning of the late $60 \mathrm{~s}$ and $70 \mathrm{~s}$, where the direction of focus was on the apparent lack of a unique knowledge base on nursing[9] This marks the first stage of nursing development as a discipline and it involved seeking differentiation and distinction from other disciplines [9]. However, we need to note that throughout the early 20th century and potentially to this day, nursing education remains through on-the-job learning and is characterized as training rather than education with programs associated with hospitals rather than colleges and universities. Additionally, much of the content of nursing programs was and arguably still to this day taught by physicians rather than nursing professors and learning predominantly being focused on the ability to perform specific actions, not on the knowledge and understanding that precedes reasoned action [23]. Some authors contend that it is much easier to describe what nurses do than what they know because the discussion on the knowledge base of nursing can be challenging. And so, nurses often fail to recognize and acknowledge the cognitive capabilities and the knowledge that goes into nursing[22].

Today, nursing research focuses on developing and testing middle-range theories and their expansion into evidence-based practice and situation-specific theories[9]. This development succeeds an era where nursing academics directed their attention onto institutional legitimacy and academic autonomy, which emphasized the need to clarify the phenomena of interest to the discipline, the ontological, epistemological, and methodological approaches appropriate for it[9].

The shift to university-based education in Morocco is highly impactful on the development and understanding of the knowledge base of nursing as it is the means to transmit the nursing knowledge base. Barich et al's findings, however, indicate that nursing education curriculums in Morocco are not yet adapted to conform fully to the bachelor, master's, Ph.D. system. They indicate that a Reform would be necessary to respond to the specificities of training in nursing and health techniques.[24]Linking areas of practice to theoretical components of nursing is essential as the very purpose of knowledge development is to improve nursing practice [9], this implies a demand for a deeper understanding of nursing as a science and its theory of knowledge.

\subsection{Social recognition and sense of belonging:}

The construction of a professional identity begins with socialization with individuals in the same field, from educators and trainers to colleagues in the clinical field[3]. Socialization 
ensures integration with the professional group and ideally results in a feeling of belonging to it, which has been shown to promote significant involvement of students in their studies[3] Additionally, it was necessary to develop job satisfaction later on and cultivate a positive social image[3]. The recognition received by the professional group for their knowledge and skills is also conducive to positive self-esteem as it impacts the value individuals give to themselves $[25,13]$. However, Nurses engage in a variety of actions that are far more subtle than in other professions that involve common skills that are directly observable. This cognitive aspect of nursing leads to a lack of recognition by the public[22]. The presence of numerous negative stereotypes on nursing aggravates the situation and impacts the selfconcept of nurses negatively, leading to limited growth of their professional identity [26].

These insights show the importance of understanding the process of socialization and how it can shape and impact future nursing professionals. Positive socialization ensures positive self-esteem. It is a prerequisite for the recruitment of nursing students and the retention of professionals[1, 27, 2, 28]. More specifically, there is an association between the presence of role models and positive supervision and positive outcomes in professional identity formation [3]. One of the other consequences is the development of a sense of humility towards resources and self-limitations, which has interpersonal consequences and implications on the working environment with a decrease in territoriality and an increase in the desire for collaboration [4]. Although some authors suggest that it is not a requirement for educational activities to focus on the development of professional identity directly, as their objective is to help clarify the role within healthcare organizations[1,29]. Others suggest that the concept needs to be included intentionally, given that enough evidence has proven its link to strengthening success, promoting trust, and improving outcomes in the formation of professionals[3]. This presents a powerful argument for the necessity to secure empirical evidence surrounding the socialization of nursing students into their profession in Morocco and inform educators and supervisors about their role in providing students with a positive self-concept. It also informs of a need to explore public perception on nursing in Morocco and work on improving nursing public image, as it strongly impacts the formation and strengthening of nurses' professional identity[26].

\subsection{Autonomy and regulation:}

Although the new regulations made in 2016 for nursing aim to provide a legal frame, modernize Moroccan nursing as a profession and clarify its responsibilities towards the population, the subordination to medicine is still prominent and acknowledged[21].

The nursing literature provides a plethora of clarifications on how Regulation affects the nursing role just as the political, cultural, and historical realities that surround professionals. As a social identity, a profession contains a responsibility to society, patients' other professions, and oneself[3]. And so, it is a type of contract between the professional and society. This responsibility is predicated on autonomy as it includes self-regulation and selfidentification [3]. The professional group, ideally, reacts autonomously but remains under a duty to meet the needs of the public it serves [8]. The presence of limits forge a structure to the professional role, so the more the role played is autonomous and includes a responsibility, the more it allows the existence of self-confidence, promotes feelings of empowerment, and reinforces a positive self-image [1]. Other authors mention that the consideration of role responsibilities is the result of a well-developed professional identity because it allows the nurse to take care of the person as a whole and meet their needs fully [4], and that is a critical part of the nursing role.

Nursing autonomy remains a point of dissension, with many scholars using this lack of self-regulation as an argument in the debate on nursing professionalization[15]. The incomplete autonomy of nursing leads to the persistence of dependency on medicine to run 
most of its practice and remain subordinate to it[9] eliciting the formation of nurses that have a hard time defining their role as this task is outsourced to others who are not from the professional group. Consequently, low rates of professional nursing identity are observed [3]. And that is not conducive to the enhancement of retention rates of nurses nor quality patient care. Willetts \& Clarke posited that to understand and describe professional identity in nursing, attention should be directed towards workplace settings, and with that, research needs to be oriented to the daily activities and the social actions of nurses[15].

Some scholars show concern that the modernization of nursing and professionalism may lead to divergence from the holistic and humanistic nature of nursing. Watson puts emphasis on caring as a basis for practice and argues for the focus on maintaining this core [30] more fundamentally, this disagreement emanates from a larger debate on the ethical grounds of nursing and lies between formal normative ethics and caring ethics. Important figures in this discussion, include Tronto, Watson, Noddings, Gilligan, Gastmans, and Little, to name a few [31]. This complexity of nursing practice comes from its relational nature that adds to the nuance around defining and clarifying the responsibilities and role of nurses. The literature and research around this relational aspect have also evolved with a notable shift of focus to more collective and shared ethical codes within organizational norms and standards rather than the previous focalization on personal values, virtues, and manners of nurses[8]. some authors consider this shift to be a consequence of the socio-demographic changes and the transition from the simple treatment of disease to promoting healthy lifestyles and disease prevention [32]

\subsection{Professional Ethics}

The legal frame for Moroccan nursing mentions the requirement of respecting the principles of morality, dignity, probity, integrity, selflessness, and professional ethics and maintaining professional secrecy [21]. Furthermore, this obligation extends to students as well. With progression towards the expansion of role responsibilities[18], ethical guidelines are becoming increasingly relevant to decision-making in nursing practice, since their absence can become a source of legal conflict. Despite that, there is an apparent lack of evaluation of the practical applications of the ethical foundations of nursing. This informs of the needed empirical evidence crucial to the eventual application of the theoretical ethical knowledge base into Moroccan healthcare facilities.

The role of ethics in nursing is fundamental. Generally, normative professional ethics aims to overcome both an internal and external need. The internal need is to define the ideology of the profession and provide advice for ethical practice by explicitly introducing professional values, responsibilities, and duties as well as the rights of professionals. The external is to inform the public of what to expect when being treated and cared for by nurses. And so, helping the profession achieve its goals $[8,33]$. The international council of nursing ICN has published an international code of ethics for nurses, the creation of this foundational document aimed to guide the preparation of national ethical codes around the world and replace the national code where none exists [34]. Even though this code of ethics emanates from different schools of thought, consideration of the cultural influence remains essential for its application within nursing education and practice. An example of this cultural influence is that of Japanese and Chinese nurses educated under the American and British bioethics textbooks with little regard for cultural differences[35]. while following the same codes, a study showed that nurses do not attach the same importance to professional values. Japanese nurses place higher importance on continuity, homogeneity, harmony, selfsacrifice, and hard work, while American nurses focus on control, diversity, choice of patient treatment, and self-protection [35]. This study highlights the impact of the social context and the interplay between personal, social values and descriptions of the profession. Recognition 
of this complex interaction is necessary, as possible differences in values can lead to conflicts with detrimental consequences. These can range from stress, anxiety, burnout to even resignation and ultimately poor patient care and failure to meet the standards and goals of the profession [5]. Watson posited that Nurses' value systems influence the actions they take, and if nurses are influenced by a robust value system, they wouldn't be willing to conform to the terms with which they disagree [30]. On the other hand, lack of professional identity leads to an observed superficial commitment to the profession and can lead to poor quality care, moral distress, values dissonance, and decreased self-confidence linked to hindered ability to make decisions [3].

Nursing professional identity is tightly linked to its ethical roots, as Ranjbar et al. [36] postulate through their research. They conceptualized the formation process of professional nursing identity as a moral development journey. Through their study, conducted on Iranian nursing students, they concluded that becoming a nurse consisted of three stages of growth: 1-knowing the identity of nursing as moral transition, 2- acceptance of nursing identity as moral reconstruction, and 3- internalization of professional identity as professional morality. [36]

Considering professional ethics as foundational to nursing professional identity formation, the different findings presented raise interest in research that seeks to understand the organizational framework for health care structures and their ability to promote the application of nursing ethical standards. Additionally, they call for further investigation into how the Moroccan social and cultural context influence what nursing ethical values nurses prioritize and use as a guide in their practice. Research in this area should also extend to the nursing educational curriculums and the extent to which they facilitate and promote the internalization of nursing values.

\section{Conclusion:}

As a professional discipline, nursing is practical and its research tends to be prescriptive [9], its practice and goals are constantly affected by changes in the socio-demographic structure, regulations, and objectives of the health system as a whole [8].

Although consensus is maintained on modern nursing meeting the criteria for professionalism[3], the translation of this development into different socio-economical contexts and cultures brings forth diverse challenges. This pushes forward interest in understanding nursing within the complexity of the concept of professional identity.

For the Moroccan context, research remains scarce on the subject and from the evaluation of the empirically verifiable documents, nursing in Morocco remains largely unstructured with many constituents of professional nursing absent. This paper maintains that universitybased education is a major and significant development in structuring nursing's professional identity in Morocco and should be leveraged for the achievement of substantial positive outcomes in areas of development of the nursing knowledge base and its application, improvement of social image, structuring autonomy, and the establishment of professional ethics.

To conclude, empirical evidence remains crucial for the utilization of nursing knowledge in decision-making and asserting the practical contribution of nursing in the achievement of healthcare objectives. This means that further research in the different components of nursing professional identity within the Moroccan context is a critical point for the development of nursing as a profession and bridging the gap between theory vs practice.

The authors acknowledge the National Center for Scientific and Technical Research (CNRST) of Morocco for their financial support. 


\section{References:}

1. P. Rasmussen, A. Henderson, N. Andrew and T. Conroy, J.Contin.Educ.Nurs. 49, 225-232. (2018)

2. S. Sabanciogullari and S. Dogan,Inte. J.Nurs.Prac. 23, 1076-1085. (2015)

3. A. Fitzgerald, Nurs.Forum. 55, 447-472 (2020)

4. J. Öhlén and K. Segesten, J Adv Nurs 28, 720-727. (1998)

5. K. Horton, V. Tschudin and A. Forget, Nurs Ethics 14, 716-740. (2007)

6. G. Thupayagale and K. Dithole, Nurs.Forum..40, 141-144. (2005),

7. E. Kinsella and A. Pitman, Phronesis as professional knowledge: Practical wisdom in the professions. .Rotterdam. Sense publishing(2012).

8. M. Kangasniemi, P. Pakkanen and A. Korhonen, J Adv Nurs 71, 1744-1757. (2015)

9. M. McEwen and E. M. Wills, Theoretical basis for nursing, LWW, Philadelphia, (2018).

10. A. Finkelman and C. Kenner, Professional nursing concepts: Competencies for quality leadership, Jones \& Bartlett Learning, Burlington, MA, (2014).

11. M. M. Styles, Int Nurs Rev 52, 81-82 (2005),

12. H. Gardner and L. S. Shulman, Daedalus $134,13-18$ (2005),

13. B. B. Caza and S. J. Creary, Perspectives on Contemporary Professional Work ,259-285, Edward Elgar Publishing (2016).

14. N. J. MacKinnon and D. R. Heise, "Theories of identities and selves," Self, identity, and social institutions, , Palgrave Macmillan US, New York, 2010, pp. 163-197.

15. G. Willetts and D. Clarke, Int. J. Nurs. Prac. 20, 164-169. (2014)

16. L. Licata, Rev. Elec. Psy. Soc. ,1, 19-33 (2007),

17. WHO, the High-Level Commission on Health Employment and Economic Growth.,Working for health and growth: Investing in the health workforce, Geneva, Switzerland, (2016).

18. ministére de la santé ,Plan de santé 2025, (2018).

19. S. El-Bakkouri, JiL.Center(2017)

20. A. Peters, R. Palomo and D. Pittet, Antimicrob Resist Infect Control 9 (2020).

21. Loi $\mathrm{n}^{\circ} 43-13$ relative à l'exercice des professions infirmières, vol. 1400 , bulletin officiel (2016).

22. B. Rodgers, The evolution of nursing science" Philosophies and theories for advanced nursing practice, Jones \& Bartlett Learning,(2010).

23. J. Butts, Philosophies and theories for advanced nursing practice, Jones \& Bartlett Learning, Sudbury, Mass, (2010).

24. F. Barich, N. Chamkal and B. Rezzouk, Rev Fran Int Re Inf.5 (2019)

25. A.M. Fray and S. Picouleau, Man.Ave. 8, 72-88. (2010)

26. Y. ten Hoeve, G. Jansen and P. Roodbol, J Adv Nurs 70, 295-309. (2014)

27. I. Wilson, L. S. Cowin, M. Johnson and H. Young, Teach Learn Med, 25, 369-373. (2013)

28. L. H. Shahidi, M. Vahidi, B. Mahram, H. N. Areshtanab and N. Zarghi, Res Dev Med Educ 3, 37-43 (2014).

29. R. L. Cruess, S. R. Cruess and Y. Steinert, Acad Med 91, 180-185. (2016)

30. J. Watson, ICUs Nurs. Web J. 9 , 7, (2002),

31. S. Edwards, Nurs. Philos. 10, 231-240. (2009)

32. H. t. Have, Encyclopedia of global bioethics., Springer International Publishing(2016).

33. M. Kangasniemi, K. Arala, E. Becker, A. Suutarla, T. Haapa and A. Korhonen, Nurs Ethics, 24, 538-555 (2017) 
34. Conseil international des infirmières, Code déontologique du cii pour la profession infirmière(2012)

35. P. L. Wros, D. Doutrich and S. Izumi, Nurs Health Sci ,6, 131-140,(2004)

36. H. Ranjbar, S. Joolaee, A. Vedadhir, A. Abbaszadeh and C. Bernstein, Nurs Ethics 24, 583-597. (2017) 